\title{
EL ERROR FATAL DE BEN BERNANKE
}

\author{
JESÚS HUERTA DE SOTO*
}

Aunque la actual crisis económica tuvo un origen monetario (la grave expansión crediticia y monetaria a reducidísimos tipos de interés orquestada por los bancos centrales en los pasados cinco años), la misma tiene actualmente una naturaleza real básicamente microeconómica: muchos empresarios, engañados por las artificiales facilidades crediticias, han invertido allí donde no debían, emprendiendo proyectos de inversión que ahora se ve que la generalidad de los ciudadanos y consumidores no están dispuesto a respaldar.

Afortunadamente, el mercado es muy ágil y rápido a la hora de detectar los errores de inversión y de manera espontánea pone en marcha los procesos necesarios (vía reducción de precios, cambio en su estructura relativa y paralización de los proyectos de inversión no viables) para afrontar la necesaria e ineludible reestructuración cuanto antes y con el mínimo coste. En esto consiste precisamente la recesión que, al igual que la resaca, no es sino el síntoma de la reacción del organismo social ante la agresión monetaria, reacción que exige un realineamiento de los precios relativos y una reducción de los de aquellos bienes producidos por error, precisamente hasta aquellos niveles en que de nuevo surjan oportunidades de beneficio empresarial, poniéndose así las bases necesarias de la ulterior y tan esperada recuperación.

El problema más grave que ahora puede plantearse consiste en que la intervención de gobiernos y bancos centrales pueda dificultar o incluso obstaculizar completamente el mencionado proceso espontáneo de reajuste. Especialmente preocupante, en este sentido, es la decisión adoptada por Ben Bernanke y su Reserva Federal, consistente en rebajar prácticamente a cero los

* Catedrático de Economía Política, Universidad Rey Juan Carlos. 
tipos de interés, inyectando en forma de créditos toda la liquidez que sea necesaria para salir de la crisis. Es claro que este tipo de políticas monetarias, lejos de acelerar la recuperación, la retrasan y dificultan, en la medida en que alargarán innecesariamente la agonía de los procesos empresariales que es preciso liquidar cuanto antes, si es que, como sucedió en Japón, no se bloquea indefinidamente la recuperación, al perder las empresas inviables todo incentivo para reestructurarse (de hecho en Japón no se ha salido de la recesión en más de una década pues el roll over indefinido de préstamos ha permitido la devolución generalizada de los préstamos morosos con otros de nueva creación, y así sucesivamente).

Son pues tres los escenarios que se abren ahora: Primero, poco probable, que la agresiva política de inyección monetaria reproduzca la burbuja (sería el peor de todos, pues sólo se lograría a costa de hacer mucho más grave una nueva recesión en el futuro que llegaría inexorablemente en el momento en que, ante el primer repunte inflacionario, se hiciera inevitable subir, aunque ligeramente, los tipos de interés). Segundo, la comentada japonización de la economía, como resultado del efecto bloqueante de la recuperación de los nuevos créditos concedidos. Y tercero, que a pesar de los grandiosos y contraproducentes planes de salvamento, a trancas y barrancas, siga su curso la necesaria reestructuración (pero con un coste y duración mucho mayores de lo que habría sido preciso). En suma, en vez de una crisis en uve, profunda y rápida (que es lo que el mercado libre propiciaría), la intervención monetaria y gubernamental fuerzan innecesariamente una recesión mucho más prolongada y dolorosa. Dada la demanda social por «hacer algo urgentemente» en tiempos de crisis y recesión económica, quizás el verdadero arte político en estos momentos consistiría en transmitir la sensación de que se está haciendo algo con un conjunto de «medidas» que por su timidez, timing y diseño, en la práctica sean inocuas y no perturben el proceso espontáneo de saneamiento que ha iniciado el mercado. Aunque lo ideal, sin duda alguna, sería contar con verdaderos estadistas que fueran capaces de explicar la verdad y lo ineludible de la actual situación, y que sólo con profundas reformas de liberalización estructural (especialmente en el 
mercado de trabajo, en el ámbito de la desregulación a todos los niveles y en el aumento de la austeridad del sector público) puede acelerarse el advenimiento de la recuperación en un entorno tan competitivo y globalizado como en el que vivimos.

Dos comentarios finales: uno sobre la deflación y otro sobre la supuesta conveniencia de fomentar el consumo. Hoy parece que se está reproduciendo la histeria antideflacionista que hace pocos años se utilizó como coartada para justificar las políticas de dinero barato que han terminado produciendo los resultados desastrosos que hoy todos conocemos. Y, sin embargo, es tan sólo la estanflación o recesión inflacionaria, la que hay que evitar a toda costa (pues es, sin duda, «el peor de los mundos»). Y es que, de hecho, y en ausencia de intervenciones contraproducentes, la deflación que resulta de la ineludible contracción crediticia que sigue a toda «burbuja», posee efectos beneficiosos: revierte las injusticias redistributivas de la fase anterior artificialmente expansiva, al favorecer a los consumidores en general, y en particular a los acreedores y perceptores de rentas fijas (pensionistas, viudas y huérfanos) y, sobre todo, hace más rápido y ágil el proceso de reconversión de las inversiones no rentables, pues son precisamente éstas las primeras que dejan de financiarse cuando llega la contracción crediticia, liberando recursos escasos que son muy necesarios en otras líneas de producción.

La idea de que es conveniente fomentar el consumo es un grave error. Recuérdese que la caída (relativa) del consumo es la consecuencia, que no la causa, de la crisis y recesión económica. Y si la percepción general es otra, ello se debe en gran medida a las carencias que tiene el concepto de PIB de la contabilidad nacional, pues indebidamente tiende a exagerar la importancia del consumo al dejar fuera de su cómputo casi dos terceras partes de la facturación global de las empresas (precisamente la que se efectúa entre las etapas intermedias del proceso productivo y que son con mucho las más afectadas por la contracción). Si la crisis ha surgido es por falta de ahorro real para sostener proyectos de inversión excesivamente ambiciosos que fueron financiados artificialmente con expansión crediticia, y sólo podremos salir de ella ahorrando más y consumiendo menos: esto es lo que, dicho sea de paso, ya están haciendo millones de empresas y agentes 
económicos, que intentan sanear sus cuentas y balances reduciendo costes y su excesivo endeudamiento. $Y$ de hecho, si muchas empresas no pueden encontrar financiación bancaria en los actuales momentos, suponiendo que sean viables, al menos podrían financiarse si sus socios ahorraran más (es decir, consumieran menos). Por tanto, toda política de expansión artificial del consumo en los actuales momentos es claramente contraproducente; nos recuerda al absurdo remedio casero contra la resaca (dar más alcohol del mismo tipo del ingerido precisamente en exceso) y puede considerarse tan irresponsable como el encargar de apagar un incendio a un grupo de pirómanos armados de lanzallamas. 